\title{
Antimalarial Prescribing Practices: A Challenge to Malaria Control in Ghana
}

\author{
B.K. Abuaku ${ }^{a}$ K.A. Koram ${ }^{a}$ F.N. Binka ${ }^{b}$ \\ ${ }^{a}$ Noguchi Memorial Institute for Medical Research and ${ }^{b}$ School of Public Health, University of Ghana, Legon, \\ Ghana
}

\section{Key Words}

Antimalarial practices · Prescribing practices ·

Malaria control · Ghana

\begin{abstract}
Objective: The study was conducted to determine antimalarial prescribing practices among prescribers in 2 of the 6 sentinel sites established to document antimalarial drug efficacy in Ghana in order to provide some explanation underlying chloroquine treatment failures in the country. Subjects and Methods: The study was descriptive combining both qualitative and quantitative designs. The qualitative design involved in-depth interviews of general prescribers in the Wassa West and Kassena Nankana districts using an interview guide. The quantitative design involved a review of Outpatient Department prescriptions of 100 patients clinically diagnosed as having malaria within the year 2000 in each of the 7 selected health care facilities. Results: The overall number of drugs prescribed per patient encounter was 4.3 in the Wassa West district and 3.0 in the Kassena Nankana district. The number of drugs per patient encounter was 5.4 and 3.7 in private and government health care facilities, respectively. The commonly prescribed antimalarial drug in all the health care facilities visited was chloroquine. However, only $9.8 \%$ of prescriptions in private health care facilities contained correct doses of chloroquine compared to $54 \%$ in government health care facilities $(p=0.000)$. Prescriptions containing chloroquine
\end{abstract}

injections were least likely to have correct doses of chloroquine. Conclusion: The findings indicate that although chloroquine remained the first-line drug in the treatment of uncomplicated malaria in the two districts, the level of appropriateness of doses prescribed was generally low. Inappropriate doses of chloroquine prescribed were more prevalent in private than government health care facilities, and among prescriptions containing injections.

Copyright $@ 2005$ S. Karger AG, Basel

\section{Introduction}

Malaria remains a major public health problem in Africa. It has been estimated that out of the over 1 million deaths caused by malaria worldwide, $90 \%$ occur in subSaharan Africa. Malaria is also directly responsible for $20 \%$ ( 1 in 5) of childhood deaths in Africa, and indirectly contributes to illness and deaths from respiratory infections, diarrheal diseases and malnutrition [1].

Malaria is endemic in Ghana, and it is estimated to account for $40 \%$ of all outpatient attendance and over $25 \%$ of under-five mortality. The current control strategy in Ghana has case management based on prompt recognition and adequate treatment as its main focus, using chloroquine as the first-line drug [2]. The emergence of chloroquine-resistant parasites in the country, first reported in 1986, and subsequent reports of sulfadoxine/ pyrimethamine (second-line drug) resistance are major

\section{KARGER}

Fax +4161306 1234

E-Mail karger@karger.ch

www.karger.com
(C) 2005 S. Karger AG, Basel

$1011-7571 / 05 / 0145-0332 \$ 22.00 / 0$

Accessible online at:

www.karger.com/mpp
Benjamin Abuaku

Noguchi Memorial Institute for Medical Research, University of Ghana, PO Box LG581 Legon (Ghana)

Tel. +23321 500374/501178, Fax +23321502182

E-Mail babuaku@noguchi.mimcom.net 
Table 1. Antimalarial drugs prescribed in the Wassa West district (WWD) and the Kassena Nankana district (KND)

\begin{tabular}{lllll}
\hline Category & $\begin{array}{l}\text { WWD } \\
(\mathrm{n}=500)\end{array}$ & $\begin{array}{l}\text { KND } \\
(\mathrm{n}=200)\end{array}$ & $\chi^{2}$ & $\mathrm{p}$ value \\
\hline $\begin{array}{l}\text { Mean number of drugs per prescription } \\
\text { Proportion of prescriptions containing }\end{array}$ & 4.3 & 3.0 & - & 0.000 \\
$\quad \begin{array}{l}\text { Chloroquine } \\
\text { Amodiaquine }\end{array}$ & $84.2 \%$ & $97 \%$ & 21.91 & 0.000 \\
Sulfadoxine/pyrimethamine & $5.6 \%$ & - & - & $0.000^{*}$ \\
Artemisinin & $2.8 \%$ & $2.0 \%$ & 0.36 & 0.546 \\
Quinine & $5.8 \%$ & - & - & $0.000^{*}$ \\
Halofantrine & $1.8 \%$ & $0.5 \%$ & - & $0.296^{*}$ \\
No antimalarial & $0.2 \%$ & - & - & $1.000^{*}$ \\
\hline
\end{tabular}

* Fisher's exact test. obstacles to the control strategy, and adversely affect malaria morbidity, mortality and health care costs [3-5]. The spread of antimalarial drug resistance is influenced by patterns of drug use among other factors such as the relative risk of drug-resistant parasites transmitting viable gametocytes compared to drug-sensitive parasites, intensity of transmission, and immunity of the human population $[6,7]$. Drug use patterns are often described in terms of prescribing and dispensing practices, and patient's use of drugs [8]. Hence this study was conducted to determine antimalarial prescribing practices in order to ascertain the reason(s) underlying chloroquine treatment failures in Ghana.

\section{Subjects and Methods}

The study was conducted in the Wassa West and the Kassena Nankana districts, 2 of the 6 sentinel districts involved in chloroquine efficacy studies in Ghana between 1998 and 2001. Five and 2 health care facilities were selected for Wassa West and Kassena Nankana districts, respectively.

The Wassa West district is a mining district with vegetation that is mainly secondary rainforest. The district has a district/government hospital, 9 rural health care facilities, 11 private clinics/hospitals, and 10 maternity homes. Malaria is hyperendemic and is the primary cause of child morbidity and mortality [9].

Kassena-Nankana district is a farming district within the Guinea Savannah woodlands. The district has a district/government hospital and 5 rural health care facilities. There is no private health care facility in the district. Malaria is holoendemic and is the leading cause of morbidity and mortality $[10,11]$. The therapeutic efficacy of chloroquine in the treatment of uncomplicated Plasmodium falciparum malaria in Wassa West and Kassena Nankana districts is estimated at 67.3 and $76.9 \%$, respectively [12].

The study was descriptive, combining both qualitative and quantitative designs. The qualitative design involved in-depth in- terviews of 15 general prescribers to determine some of the factors influencing prescribing practices using an interview guide. The quantitative design involved a review of Outpatient Department prescriptions of 100 patients clinically diagnosed as having malaria within the year 2000 in each selected health care facility. The number and types of drugs prescribed were determined. Prescriptions containing chloroquine were rated as appropriate or inappropriate based on the standard treatment guidelines of the Ministry of Health (i.e. $25 \mathrm{mg} / \mathrm{kg}$ body weight given over 3 days as $10 \mathrm{mg} / \mathrm{kg}$, $10 \mathrm{mg} / \mathrm{kg}$, and $5 \mathrm{mg} / \mathrm{kg}$ ).

A total of 700 Outpatient Department cards of patients who had sought for malaria treatment in 7 selected health care facilities during the year 2000 were randomly selected and reviewed: Wassa West district hospital $(\mathrm{n}=1)$; Wassa West rural health facilities $(\mathrm{n}=2)$; Wassa West private health facilities $(\mathrm{n}=2)$; Kassena Nankana district hospital $(\mathrm{n}=1)$, and Kassena Nankana rural health facilities $(\mathrm{n}=1)$.

Qualitative data were analyzed using the Textbase Beta ${ }^{\circledR}$ software. Coding and categorization of statements were performed followed by content analysis. Quantitative data were analyzed using the Statistical Package for Social Sciences (SPSS version 10 for Windows). Chi-square $\left(\chi^{2}\right)$ tests were used to compare proportions of appropriate prescriptions between private and government health care facilities.

The study received approval from the Institutional Review Board of the Noguchi Memorial Institute for Medical Research, University of Ghana, Legon.

\section{Results}

\section{Number of Drugs Prescribed per Malaria Encounter}

The mean number of malaria drugs per encounter was 4.3 and 3.0 in the Wassa West and Kassena Nankana districts, respectively. The difference was statistically significant; $\mathrm{p}=0.000$ (table 1 ). Within the Wassa West district, the mean number of drugs per encounter was 3.7 in the district hospital (table 2); also 3.7 in government 
Table 2. Antimalarial drugs prescribed in the Wassa West district hospital (WWDH) and the Kassena Nankana district hospital (KNDH)
Table 3. Antimalarial drugs prescribed in government and private health facilities in the Wassa West district

\begin{tabular}{lcccc}
\hline Category & $\begin{array}{l}\text { WWDH } \\
(\mathrm{n}=100)\end{array}$ & $\begin{array}{l}\text { KNDH } \\
\mathrm{n}=100)\end{array}$ & $\chi^{2}$ & $\mathrm{p}$ value \\
\hline $\begin{array}{l}\text { Mean number of drugs per prescription } \\
\text { Proportion of prescriptions containing }\end{array}$ & 3.7 & 3.1 & - & 0.000 \\
$\quad$ Chloroquine & $79 \%$ & $95 \%$ & 11.26 & 0.001 \\
$\quad$ Amodiaquine & $15 \%$ & - & - & $0.000^{*}$ \\
$\quad$ Sulfadoxine/pyrimethamine & $4 \%$ & $4 \%$ & - & $1.000^{*}$ \\
$\quad$ Artemisinin & $2 \%$ & - & - & $0.497^{*}$ \\
$\quad$ Quinine & - & $1 \%$ & - & $1.000^{*}$ \\
\hline
\end{tabular}

* Fisher's exact test.

\begin{tabular}{lllll}
\hline Category & $\begin{array}{l}\text { Government } \\
(\mathrm{n}=300)\end{array}$ & $\begin{array}{l}\text { Private } \\
(\mathrm{n}=200)\end{array}$ & $\chi^{2}$ & $\mathrm{p}$ value \\
\hline $\begin{array}{l}\text { Mean number of drugs per prescription } \\
\text { Proportion of prescriptions containing }\end{array}$ & 3.7 & 5.4 & - & 0.000 \\
$\quad$ Chloroquine & $92.7 \%$ & $71.5 \%$ & 40.33 & 0.000 \\
Amodiaquine & $5 \%$ & $6.5 \%$ & 0.51 & 0.475 \\
Sulfadoxine/pyrimethamine & $1.3 \%$ & $5 \%$ & 5.92 & 0.015 \\
$\quad$ Artemisinin & $1 \%$ & $13 \%$ & 31.56 & 0.000 \\
Quinine & - & $4.5 \%$ & - & $0.000^{*}$ \\
$\quad$ Halofantrine & - & $0.5 \%$ & - & $0.400^{*}$ \\
\hline
\end{tabular}

* Fisher's exact test. health care facilities but 5.4 in private health care facilities (table 3). The mean difference between government and private health facilities was statistically significant $(p=0.000)$. Within the Kassena Nankana district, the mean number of drugs per encounter was 3.1 in the district hospital (table 2) and 2.9 in the rural health care facility visited (data not shown). The mean difference between the Wassa West and the Kassena Nankana district hospitals was statistically significant $(\mathrm{p}=0.000)$ (tables 2, 3).

\section{Types of Antimalarial Drugs Prescribed for Malaria Cases}

The most commonly prescribed antimalarial drug in all the health care facilities was chloroquine. However, the proportion of prescriptions containing chloroquine was significantly higher in the Kassena Nankana district $(97 \%)$ than in the Wassa West district $(84.2 \%, \mathrm{p}=0.000)$ (tables 1,2). Though prescriptions in both government and private health care facilities contained chloroquine in the Wassa West district, the proportion was signifi- cantly higher in the government health care $(92.7 \%)$ than in private health care facilities $(71.5 \%, \mathrm{p}=0.000)$ (table 3). Other antimalarials prescribed in the Wassa West district were amodiaquine, sulfadoxine/pyrimethamine, artemisinin, quinine and halofantrine, and those prescribed in the Kassena Nankana district were sulfadoxine/pyrimethamine, and quinine. The tendency to prescribe amodiaquine or artemisinin was significantly higher in the Wassa West than in Kassena Nankana district (table 1).

\section{Appropriateness of Doses of First-Line Drug, Chloroquine, Prescribed}

Within the Wassa West district, 54\% of prescriptions in government health care facilities (district hospital and rural health care facilities) contained appropriate chloroquine dose whilst only $9.8 \%$ of the prescriptions in the private health care facilities contained appropriate chloroquine dose (table 4). The difference between the government and private health care facilities was statistically significant $(p=0.000)$. There was, however, no signifi- 
Table 4. Appropriateness of prescriptions containing chloroquine and proportion of prescriptions containing chloroquine injection

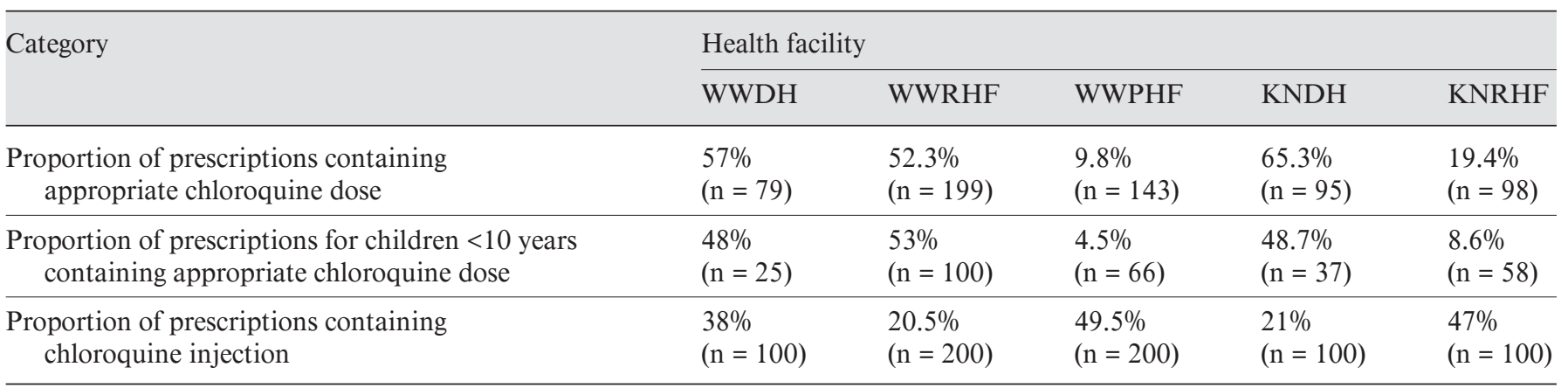

WWDH = Wassa West district hospital; WWRHF = Wassa West rural health facilities; WWPHF = Wassa West private health facilities; KNDH = Kassena Nankana district hospital; KNRHF = Kassena Nankana rural health facilities.

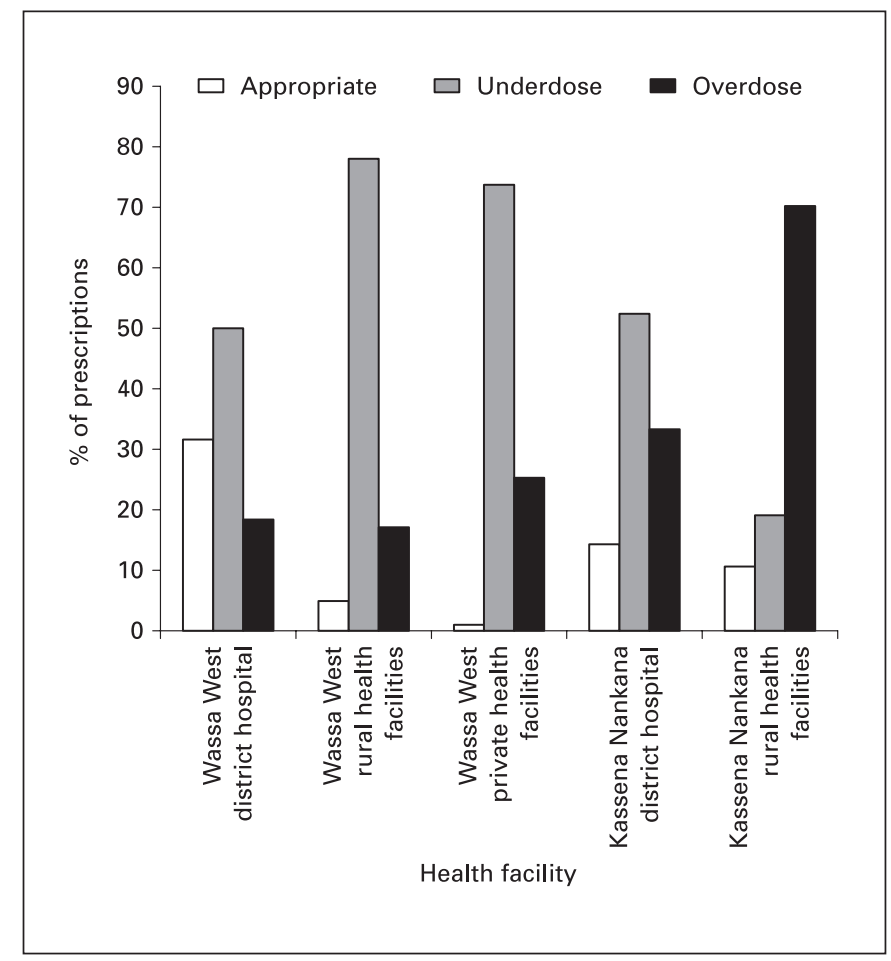

Fig. 1. Classification of total chloroquine dose on prescriptions containing chloroquine injection.

cant difference between the district hospital (urban) and the rural health care facilities visited in the district $(\mathrm{p}=$ $0.939)$.

In the Kassena Nankana district there was a significant difference in the prescriptions by health care providers in the district hospital and the rural health care facility vis- ited in terms of appropriateness of doses of chloroquine prescribed (65.3 vs. $19.4 \% ; p=0.000)$.

Less than $50 \%$ of prescriptions in the facilities visited contained chloroquine injections (table 4). However, with the exception of the rural health facility in the Kassena Nankana district, greater proportions of all prescriptions with chloroquine injections contained underdose of chloroquine (fig. 1).

\section{Factors Influencing Prescribing Patterns}

Interviews with prescribers revealed that common factors determining the type of antimalaria drug prescribed were cost, clinical state of the patient (acute or not), prescribers' personal experiences with the available antimalarials and patients' drug history prior to visiting the health care facility. Other factors were side effects of the drug, whether the patient was a Ghanaian or an expatriate, patient's choice and the experiences with the drugs, research findings, and treatment guidelines from the Ministry of Health (table 5). Prescribers in the private health care facilities said they considered the patient's choice for the sake of treatment adherence. Expatriate patients were given single-dose therapies because it was alleged that they were not complying with divided-dose therapies.

\section{Discussion}

The mean numbers of drugs per malaria patient encounter in government health care facilities, irrespective of whether they were urban or rural, were similar in the 2 districts. There were, however, significant differences between government and private health care facilities in 
Table 5. Factors influencing prescribing patterns among prescribers

\begin{tabular}{lllllll}
\hline Category & \multicolumn{2}{l}{ Health facility } & & \\
\cline { 2 - 7 } & $\begin{array}{l}\text { WWDH } \\
(\mathrm{n}=4)\end{array}$ & $\begin{array}{l}\text { WWRHF } \\
(\mathrm{n}=3)\end{array}$ & $\begin{array}{l}\text { WWPHF } \\
(\mathrm{n}=3)\end{array}$ & $\begin{array}{l}\text { KNDH } \\
(\mathrm{n}=3)\end{array}$ & $\begin{array}{l}\text { KNRHF } \\
(\mathrm{n}=2)\end{array}$ & $\begin{array}{l}\text { total } \\
(\mathrm{n}=15)\end{array}$ \\
\hline Cost of drug & 2 & 2 & - & 2 & - & 6 \\
Clinical state of patient & 4 & 3 & 2 & 2 & - & 11 \\
Personal experience & 2 & 1 & - & - & - & 3 \\
Patient's drug history & 3 & 3 & 1 & 2 & 2 & 11 \\
Side effects of drug & 3 & 3 & - & - & - & 6 \\
Ghanaian or expatriate & - & 2 & - & - & - & 2 \\
Patient's choice and experiences & 2 & 3 & 1 & - & - & 6 \\
Research findings & 2 & 1 & - & - & - & 3 \\
Treatment guidelines & 2 & - & 2 & 3 & 2 & 9 \\
\hline
\end{tabular}

WWDH = Wassa West district hospital; WWRHF = Wassa West rural health facilities; WWPHF = Wassa West private health facilities; KNDH = Kassena Nankana district hospital; KNRHF = Kassena Nankana rural health facilities.

the Wassa West district. Whereas the mean number of drugs per encounter in the government health care facilities was 3.7, that for private health care facilities was 5.4. The mean number of drugs per prescription (3.7) in government health care facilities in the Wassa West district shows a $23 \%$ decline over the number (4.8) observed in the district by Bosu and Ofori-Adjei [13], who looked at prescriptions for all patients irrespective of the diagnosis. The difference is probably due to the prescribers' participation in continuing educational programs organized by the Ghana Medical and Dental Council. It is also likely that patients diagnosed as having malaria tend to receive fewer drugs than those with other diseases. The mean numbers of drugs per prescription in all the facilities were higher than WHO's average of 2 or less, but generally lower than the national average of 4.6 [14]. A continuing downward trend of number of drugs per prescription will indicate that outpatient treatment is becoming more and more specific. Prescriptions for malaria patients in rural health care facilities in the Wassa West district were more likely to contain chloroquine compared with prescriptions from the district hospital. There was, however, no significant difference between the district hospital in the Kassena Nankana district and the rural health care facilities visited in the same district. These observations could probably be explained by the relatively higher number of Medical Assistants in the Kassena Nankana district hospital $(\mathrm{n}=3)$ compared to the Wassa West district hospital $(\mathrm{n}=1)$. The Medical Assistants (i.e. clinical nurses with 2 years' training in clini- cal medicine) are the main prescribers in rural health care facilities and so if their number is relatively higher in an urban setting, their prescription patterns may not be different from that of their colleagues in rural health care facilities.

The study also showed that prescribers in government health care facilities in the Wassa West district were more likely to prescribe correct dose of chloroquine than their counterparts in private health care facilities. This finding suggests that prescribers in government health care facilities tend to follow national treatment guidelines more than prescribers in private health care facilities. Although there are no regional studies to compare these findings with, the trend compares very well with findings by Siddiqi et al. [15] that polypharmacy was more prevalent in private health care facilities than in government health care facilities in Pakistan. Additionally, Håkansson et al. [16] found that general practitioners in Växjö, southern Sweden, had a higher degree of adherence to recommendations by the formulary committee than other categories of physicians, particularly private physicians. These findings pose a great challenge to national treatment policies that are aimed at improving quality of care at all levels.

The finding in the Wassa West district that between 20.5 and $38 \%$ of prescriptions in government health facilities contained an injection is far below the $80 \%$ observed by Bosu and Ofori-Adjei [13] in the same district. This difference, as stated earlier, could be due to the fact that the current study was limited to malaria cases and also that the former study covered a greater number of 
health care facilities. Nevertheless, a retrospective and prospective review of outpatient prescriptions in 20 dispensaries in Dar es Salaam, Tanzania, showed that between 24.6 and $34 \%$ of prescriptions contained an injection [17]. Other studies in Africa have shown that the proportion of prescriptions containing an injection range between 17.3\% in Morocco and 37\% in Ethiopia [18-22]. These regional findings compare well with the findings of this study.

\section{Conclusion}

The findings indicate that although chloroquine remained the first-line drug in the treatment of uncomplicated malaria in the 2 districts, the level of appropriate- ness of doses prescribed was generally low. Inappropriate doses of chloroquine prescribed and prescriptions containing injections were more prevalent in private than government health care facilities.

\section{Acknowledgments}

We wish to thank the Wassa West and the Kassena Nankana district Directors of Health Services, Drs. Avotri and Enos, for their warm reception. Our thanks also go to all prescribers interviewed in the 7 health facilities visited, and also the officers in charge of records in the various health facilities for helping with the selection of the outpatient cards.

This study was supported by the Multilateral Initiative on Malaria (MIM)/WHO Special Program for Research and Training in Tropical Diseases (TDR) grant ID 980034.

\section{References}

1 World Health Organization: The World Health Report 1999: Making a Difference. Geneva, World Health Organization, 1999, p 49.

2 Ghana Ministry of Health: Draft, Rollback Malaria Strategic Plan for Ghana: 2000-2010. Accra, Ministry of Health, 1999.

-3 Neequaye J: In vivo chloroquine-resistant falciparum in western Africa. Lancet 1986;i:153.

4 Landgraf B, Kollaritsch H, Wiedermann G, Wernsdorfer H: Plasmodium falciparum: susceptibility in vitro and in vivo to chloroquine and sulfadoxine-pyrimethamine in Ghanaian school children. Trans R Soc Trop Med Hyg 1994;88:440-442.

5 Afari EA, Akanmori BD, Nankano T, OforiAdjei D: Plasmodium falciparum: sensitivity to chloroquine in-vivo in three ecological zones in Ghana. Trans R Soc Trop Med Hyg 1992; 86:231-232.

6 Kitua AY: Antimalarial drug policy: making systematic change. Lancet 1999;354(suppl): SIV 32.

7 White N: Antimalarial drug resistance and combination chemotherapy. Philos Trans R Soc Lond B 1999;354:739-749.

8 Quick JD, Laing RO, Ross-Degnan D: Intervention research to promote clinically effective and economically efficient use of pharmaceuticals: the international network for rational use of drugs. J Clin Epidemiol 1991;44(suppl 2):57S-65S
9 Akabzaa T, Darimani A: Impact of Mining Sector Investment in Ghana: A Study of the Tarkwa Mining Region, 2001.

10 Binka FN, Morris SS, Ross DA, Arthur P, Aryeetey ME: Patterns of malaria morbidity and mortality in northern Ghana. Trans R Soc Trop Med Hyg 1994;88:381-385.

11 Binka FN, Maude GH, Gyapong M, Ross DA Smith PG: Risk factors for child mortality in northern Ghana: a case-control study. Int J Epidemiol 1995;24:127-135.

12 Koram KA: Mapping response of Plasmodium falciparum to chloroquine and other antimalarial drugs in Ghana, Project ID 980034. Final report submitted to MIM/TDR, 2003.

13 Bosu WK, Ofori-Adjei D: An audit of prescribing in health care facilities of the Wassa West district of Ghana. West Afr J Med 2000;19: 298-303.

14 Ghana Ministry of Health: Baseline study on the pharmaceutical sector in Ghana: Rational use, procurement and financing of drugs. Final Report 1999, p 22.

15 Siddiqi S, Hamid S, Rafique G, Chaudhry SA, Ali N, Shahab S, Sauerborn R: Prescription practices of public and private health care providers in Attock District of Pakistan. Int J Health Plann Management 2002;17:23-40.
- 16 Håkansson A, Andersson H, Cars H, Melander A: Pharmacoepidemiology and prescription: prescribing. Prescription costs and adherence to formulary committee recommendations: long-term differences between physicians in public and private care. Eur J Clin Pharmacol 2001;57:65-70.

17 Massele AY, Ofori-Adjei D, Laing RO: A study of prescribing patterns with special reference to drug use indicators in Dar es Salaam region, Tanzania. Trop Doct 1993;23:104-107.

18 Desta Z, Abula T, Beyene L, Fantahun M, Yohannes AG, Ayalew S: Assessment of rational drug use and prescribing in primary health care facilities in northwest Ethiopia. East Afr Med J 1997;74:758-763.

19 Massele AY, Mwaluko GM: A study of prescribing patterns at different health care facilities in Dar es Salaam, Tanzania. East Afr Med J 1994;71:314-316.

20 Massele AY, Nsimba SE, Rimoy G: Prescribing habits in church-owned primary health care facilities in Dar es Salaam and other Tanzanian coast regions. East Afr Med J 2001;78: 510-514.

-21 Simon N, Hakkou F, Minani M, Jasson M, Diquet B: Drug prescription and utilization in Morocco. Therapie 1998;53:113-120.

-22 Trap B, Hansen EH, Hogerzeil HV: Prescription habits of dispensing and non-dispensing doctors in Zimbabwe. Health Policy Plann 2002; 17:288-295. 